\title{
Surgery-Related Complications and Sequelae in Management of Tuberculosis of Spine
}

\author{
Myung-Sang Moon ${ }^{1}$, Sung-Soo Kim ${ }^{1}$, Young-Wan Moon ${ }^{2}$, Hanlim Moon ${ }^{3}$, Sung-Sim Kim ${ }^{4}$ \\ ${ }^{I}$ Department of Orthopedic Surgery, Cheju Halla General Hospital, Jeju, Korea \\ ${ }^{2}$ Department of Orthopedic Surgery, Samsung Medical Center, Sungkyunkwan University School of Medicine, Seoul, Korea \\ ${ }^{3}$ CUREnCARE Research, Seoul, Korea \\ ${ }^{4}$ Moon-Kim's Institute of Orthopedic Research, Seoul, Korea
}

\begin{abstract}
Study Design: Medical record-based survey.
Purpose: To survey the overall incidence of the intra- and postoperative complications and sequelae, and to propose the preventive measures to reduce complications in the spinal tuberculosis surgery.

Overview of Literature: There is no study focused on the surgery-related complications and sequelae, with some touching lightly on the clinical problems.

Methods: There were 901 patients in this study, including 92 paraplegics. One hundred eighty-six patients had no visible deformity, while those of 715 patients were visible. Six hundred fifty-nine patients had slight to moderate non-rigid kyphosis, and 56 had severe rigid kyphosis. Sixty-seven out of 92 paraplegics had slight to moderate non-rigid kyphosis, and 25 had severe kyphosis. There were 134 cervical and cervicodorsal lesions, 518 thoracic and thoracolumbar lesions, and 249 lumbar and lumbosacral lesions. Seven hundred sixty-four patients had primarily anterior surgeries, and 137 had posterior surgeries. Instrumentation surgery was combined in 174 patients.

Results: There were intra- and postoperative complications: direct large vessel and neurological injuries (cord, roots, nerves), late thrombophlebitis, various thoracic cavity problems, esophagus and ureter injuries, peritoneum perforation, ileus, wound infections, stabilization failure, increase of deformity and late adjacent joint and bone problems. Thrombophlebitis and sympatheticolysis symptoms and signs in the lower limbs were the most common complications related with anterior lumbar and lumbosacral surgeries. Kyphosis increased in $31.5 \%$ of the non-instrumented anterior surgery cases (42\% in children and $21 \%$ in adults).

Conclusions: The safe, effective and most familiar surgical procedure should be adopted to minimize complications and sequelae. Cosmetic spinal surgery should be withheld if functional improvement could not be expected.
\end{abstract}

Keywords: Tuberculosis; Spine; Therapeutics; Surgery; Complications

\section{Introduction}

There is a substantial body of literature on the surgical management of spinal tuberculosis. The studies deal largely with the methods and results of the management [1-10]: the surgical management of the different lesions and reconstruction of the surgical defect; and deformity correction and stabilization [11-17]. There were studies

Received Dec 2, 2013; Revised Dec 26, 2013; Accepted Dec 28, 2013

Corresponding author: Sung-Soo Kim

Department of Orthopedic Surgery, Cheju Halla General Hospital,

65 Doryeong-ro, Jeju 690-766, Korea

Tel: +82-64-740-5030, Fax: +82-64-743-3110, E-mail: skimos@hotmail.co.kr 
Table 1. Total surgical cases of tuberculosis of spine

\begin{tabular}{|c|c|c|c|c|c|c|c|c|}
\hline & $\begin{array}{c}\text { Anterior } \\
\ln =764 ; 16\end{array}$ & $\begin{array}{l}\text { approach } \\
y / 595)(82\end{array}$ & & & & $\begin{array}{l}\text { Posterior appro } \\
(\mathrm{n}=137 ; 60 / 77)\end{array}$ & $\begin{array}{l}\text { ach } \\
82)^{\text {a) }}\end{array}$ & \\
\hline No. & $\begin{array}{l}\text { Children/ } \\
\text { adults }\end{array}$ & No. & $\begin{array}{l}\text { Children/ } \\
\text { adults }\end{array}$ & & No. & Children/adults & No. & $\begin{array}{l}\text { Children/ } \\
\text { adults }\end{array}$ \\
\hline $126(12)^{a)}$ & 28/98 & $\begin{array}{l}118(12 \\
\text { plating })^{\text {a) }}\end{array}$ & $20 / 98$ & Cervical & 0 & $0 / 0$ & - & - \\
\hline & & 8 & $8 / 0$ & $\begin{array}{l}\text { Cervico- } \\
\text { dorsal }\end{array}$ & 8 & $0 / 8$ & - & - \\
\hline $417(67)^{\mathrm{a})}$ & $43 / 374$ & $125(13)^{b)}$ & $21 / 104$ & Dorsal & $101^{\text {a) }}$ & $60 / 41$ & $\begin{array}{r}\text { PLF: } 43 \\
36\end{array}$ & $\begin{array}{l}34 / 9 \\
27 / 9^{b)}\end{array}$ \\
\hline & & & & & & & $\begin{array}{l}\text { Posterior } \\
\text { instrumentation } \\
\text { alone: } 20\end{array}$ & $0 / 20^{b)}$ \\
\hline & - & $292(54)^{b)}$ & $22 / 270$ & Dorsolumbar & $67^{\text {a) }}$ & $\left(16\left[4^{c}\right] / 51\right)^{b)}$ & ISW+C: 4 & $4 / 0^{c)}$ \\
\hline & & & & & & & $\begin{array}{l}\text { Decompression } \\
\text { alone: } 27\end{array}$ & $20 / 7$ \\
\hline & & & & & & & $\begin{array}{l}\text { Decompression } \\
\text { and PLF: } 7^{\text {b) }}\end{array}$ & $2 / 5^{b)}$ \\
\hline $221^{\text {a) }}$ & $58 / 163$ & $\begin{array}{r}183 \\
21\end{array}$ & $\begin{array}{l}47 / 136 \\
12^{a \mid}+9^{b /}\end{array}$ & Lumbar & $\begin{array}{l}\text { Posterior } \\
\text { instrumentation } \\
+ \text { AlF: } 28^{\text {b) }}\end{array}$ & $0 / 28^{b)}$ & - & - \\
\hline & - & $38(7)^{b)}$ & $11 / 27$ & $\begin{array}{l}\text { Lumbo- } \\
\text { sacral }\end{array}$ & - & - & - & - \\
\hline Deformity & kyphosis) & & & & & $\begin{array}{l}\text { Slight to moderate } \\
\text { non-rigid kyphosis } \\
\text { (n=659) }\end{array}$ & & $122 / 537$ \\
\hline & & & & & & $\begin{array}{l}\text { Severe kyphosis } \\
(n=56)\end{array}$ & & $19 / 37$ \\
\hline & & & & & & $\begin{array}{l}\text { Paraplegies ( } n=92 \text { ): } \\
72 \text { anterior } \\
\text { decompression+AlF; } \\
18 \text { costotransversectomy; } \\
2 \text { posterior } \\
\text { instrumentation alone }\end{array}$ & & $27 / 65$ \\
\hline
\end{tabular}

$\mathrm{n}=901$ (229 children /672 adults) (809 nonparaplegics/92 paraplegics [27 children /65 adults])

Total number of instrumentation ( $n=174)$.

$n=150$ : posterior instrumentation plus AIF ( $n=87)$, posterior instrumentation plus PLF $(n=43)$, posterior instrumentation alone $(n=20)$.

Anterior instrumentation+AIF ( $n=24)$ : cervical $(n=12)$, lumbar $(n=12)$.

PLF, posterolateral fusion; AIF, anterior interbody fusion.

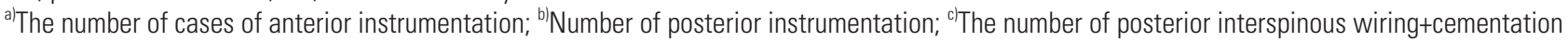
(ISW+C).

on the overall healing and fusion rates, residual kyphosis [7], bone graft complications, surgical method of reconstruction, deformity correction methodology and its effectiveness [7,10,18-24], instrument-aided posterior versus anterior surgical deformity correction and stabilization for maintenance of the corrected curve and neurological change $[10-14,16,24]$. However, none of the studies have dealt solely with the surgery-related complications, its residuals, limitation of surgery and failure rates of surgery.

It is important to understand the nature of spinal tuberculosis and surgical indications for the complicated tuberculosis, as based on the level of lesions, severity of deformity and neurology (Table 1). If the accepted treat- 
ment guidelines are strictly kept, the surgical complications and its residuals would be reduced and/or prevented with successful management outcomes. The objective of this retrospective study is to survey the overall incidence of the intra- and postoperative complications and sequelae, and to propose the prophylactic measures to minimize or reduce complications.

\section{Materials and Methods}

The subjects of this study were 901 surgically treated patients under the cover of antitubercular chemotherapy between 1968 and 2012 at the affiliated hospitals in the Republic of Korea: Catholic University of Korea, Dongshin General Hospital (Seoul), Sun General Hospital (Daejeon, Korea) and Cheju Halla General Hospital (Jeju, Korea). Sixteen surgeons had participated in the surgeries; and 764 anterior and 137 posterior surgeries were primarily carried out (Table 1).

Among the 901 patients, there were 229 children and 672 adults; and among them 92 (65 adults and 27 children) were paraplegics initially. One hundred eighty-six patients had no visible deformity, while 715 had visible ones. Six hundred fifty-nine patients (122 children and 537 adults) had slight to moderate non-rigid kyphosis; and 56 had severe rigid kyphosis (19 children and 37 adults). Sixty-seven (11 children and 56 adults) out of 92 paraplegics had slight to moderate non-rigid kyphosis; 25 paraplegics (6 children and 19 adults) had severe kyphosis; and 8 were late-onset paralytics.

For 134 cervical and cervicodorsal lesions, 126 anterior surgery (12 anterior plating) alone and 8 posterior surgery alone were performed. For 518 thoracic and thoracolumbar lesions, 417 (143 children and 274 adults) anterior and 101 (60 children and 41 adults) posterior surgeries were done. For the 249 lumbar and lumbosacral lesions, there were 221 (58 children and 163 adults) primary anterior approaches and 28 posterior approaches. Among the 221 anterior surgery cases, 183 (47 children and 136 adults) were lumbar and 38 (11 children and 27 adults) were lumbosacral lesions.

The instrumented patients numbered a total of 174:24 had anterior instrumentation (12 in cervical and 12 in lumbar spines); and 150 had posterior instrumentation (83 had combined anterior interbody fusion [AIF], and 67 had other posterior procedures alone). Among the 92 paraplegics (29 children and 63 adults), anterior de- compression and non-instrumented anterior fusion were done in 72 paraplegics, costotransversectomy alone in 18 and posterior instrumentation alone in 2 .

\section{Results}

\section{Overall intraoperative complications}

The intraoperative complications are summarized in Tables 2, 3. The most formidable intraoperative complications were the large vessel injuries (aorta ruptures in two [one by chisel], vena cava in one and iliac vein rupture in four cases) and cord injuries in six. Two patients of aorta rupture expired. There were direct cord injuries in six (3 out of 764 anterior surgery-related; and 3 out of 137 posterior surgery-related) and dural tears in twenty-four (16 in anterior surgery; and 8 in posterior surgery). One cord injury was caused by the malpositioned anterior strut graft into the canal (Fig. 1). Among the three cord injuries during posterior procedures were one by costotransversectomy procedure and two by posterior corrective osteotomy procedure. There were one transient recurrent laryngeal nerve palsy and two esophagus perforations.

Of twenty-four dura torn during decompression surgeries were eight posterior and sixteen anterior decompression. There were six thoracic root injuries. Of thirtytwo lumbar and lumbosacral surgeries, there was one Sudek's atrophy in left-arm after anterior cervical surgery as well as sympatheticolysis symptoms in lower extremities. Respiratory distress complications were observed in 43 patients: 5 related with anterior cervical surgery and 38 with thoracic surgery (Table 3 ).

Postoperatively there were wound infections in twelve, graft donor site infection in eight, lower limb thrombophlebitis in 26 cases (8 after anterior thoracic surgery; and 18 after anterior lumbar and lumbosacral surgeries) and paralytic ileus in seven after anterior lumbar surgery (Tables 1-3). The bone graft failures and sagging were observed in one hundred and eight cases (14.3\%) after noninstrumented AIF (Tables 2, 3).

\section{Posterior surgery-related complications}

Interspinous wire fixation in four children failed to provide stability. There were three direct cord injuries: one during costotransversectomy and two during osteotomy. The cord bruise with dural tear during lower dorsal de- 
Table 2. Intraoperative and postoperative complications and residuals

\begin{tabular}{|c|c|c|c|}
\hline Intraoperative & No. & Postoperative & No. $(\%)$ \\
\hline Vessels & 4 & Death (cerebral embolism due to thoromboembolism in a paraparetic) & 1 \\
\hline Aorta & 2 (death) & Respiratory complication (distress) & 43 \\
\hline Vena cava & 1 & Cervical surgery related & 5 \\
\hline liac vein & 4 & Thoracic surgery related & 38 \\
\hline Esophagus & 2 & Pneumothorax & 12 \\
\hline Lung damage & 8 & Hemothorax & 6 \\
\hline Ureter & 1 & Pleural effusion & 4 \\
\hline Peritoneal perforation & 8 & Lung atelectasis & 6 \\
\hline Neural tissues & & Pulmonary edema & 4 \\
\hline Cord & & Penumonia & 6 \\
\hline Damage & 5 & Hiccup (diaphragmatic crus irritation) & 3 \\
\hline Anterior urgery & $3 / 764$ & Local complications & 21 \\
\hline Posterior surgery & $3 / 137$ & SSI: wound infection (mixed) & 12 \\
\hline Bruise & 8 & Donor site (bone) infection & 8 \\
\hline Dural tear & 24 & Donor site iliac bone fracture & 1 \\
\hline Anterior & 16 & Thrombophlebitis in lower extremity & 26 \\
\hline Posterior & 8 & Thoracic surgery & 8 \\
\hline Root injury (thoracic) & 6 & Lumbar surgery & 18 \\
\hline Intercostal nerve cut & 8 & Neurological complications: & 3 \\
\hline \multirow[t]{21}{*}{ Symphatheticolysis } & 32 & Transient re-paralysis ${ }^{\text {a) }}$ (below T8: cause unknown) & 1 \\
\hline & & Recurrent laryngeal nerve palsy (transient) & 1 \\
\hline & & Peroneal palsy & 2 \\
\hline & & Intercostal neuroma & 8 \\
\hline & & Intercostal neuralgia & 7 \\
\hline & & Symphatheticolysis in lower extremity & 32 \\
\hline & & Sudeck's atrophy in upper extremity & 1 \\
\hline & & Loosening of rods (Steinmann pins) & 1 \\
\hline & & Wound disruption & 6 \\
\hline & & lleus & 8 \\
\hline & & No neurological recovery (65 adult paraplegics) & $7(10.7)$ \\
\hline & & $\begin{array}{l}\text { Graft problems (absorption, fracture, bed failure) } \\
\text { (among } 518 \text { uninstrumented AIF) }\end{array}$ & $108(14.3)$ \\
\hline & & Cervical & 26 \\
\hline & & Dorsal & 37 \\
\hline & & Lumbar & 45 \\
\hline & & Graft slip-out & 18 \\
\hline & & Cervical & 6 \\
\hline & & Dorsal & 5 \\
\hline & & Lumbar & 7 \\
\hline & & Kyphosis increase & $205(32)$ \\
\hline & & Children & $97(43)$ \\
\hline
\end{tabular}


Table 2. Continued

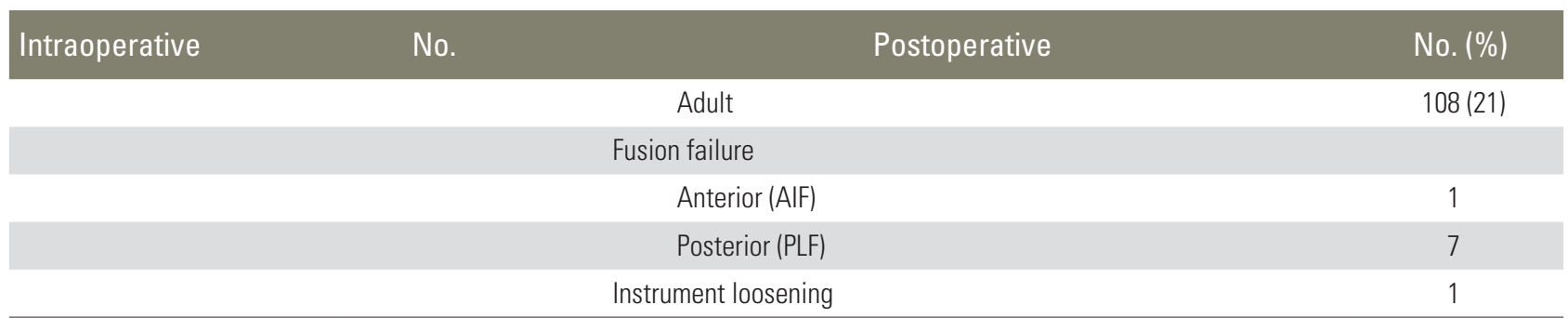

I, number of complication/total numbers subjected to surgery.

n=901 (764 anterior and 137 posterior surgeries).

AIF, anterior interbody fusion; PLF, posterolateral fusion.

Table 3. Complication related with anterior surgeries in each spinal level (cervical, dorsal, thoracolumbar, lumbar and lumbosacral spines) (764 cases)

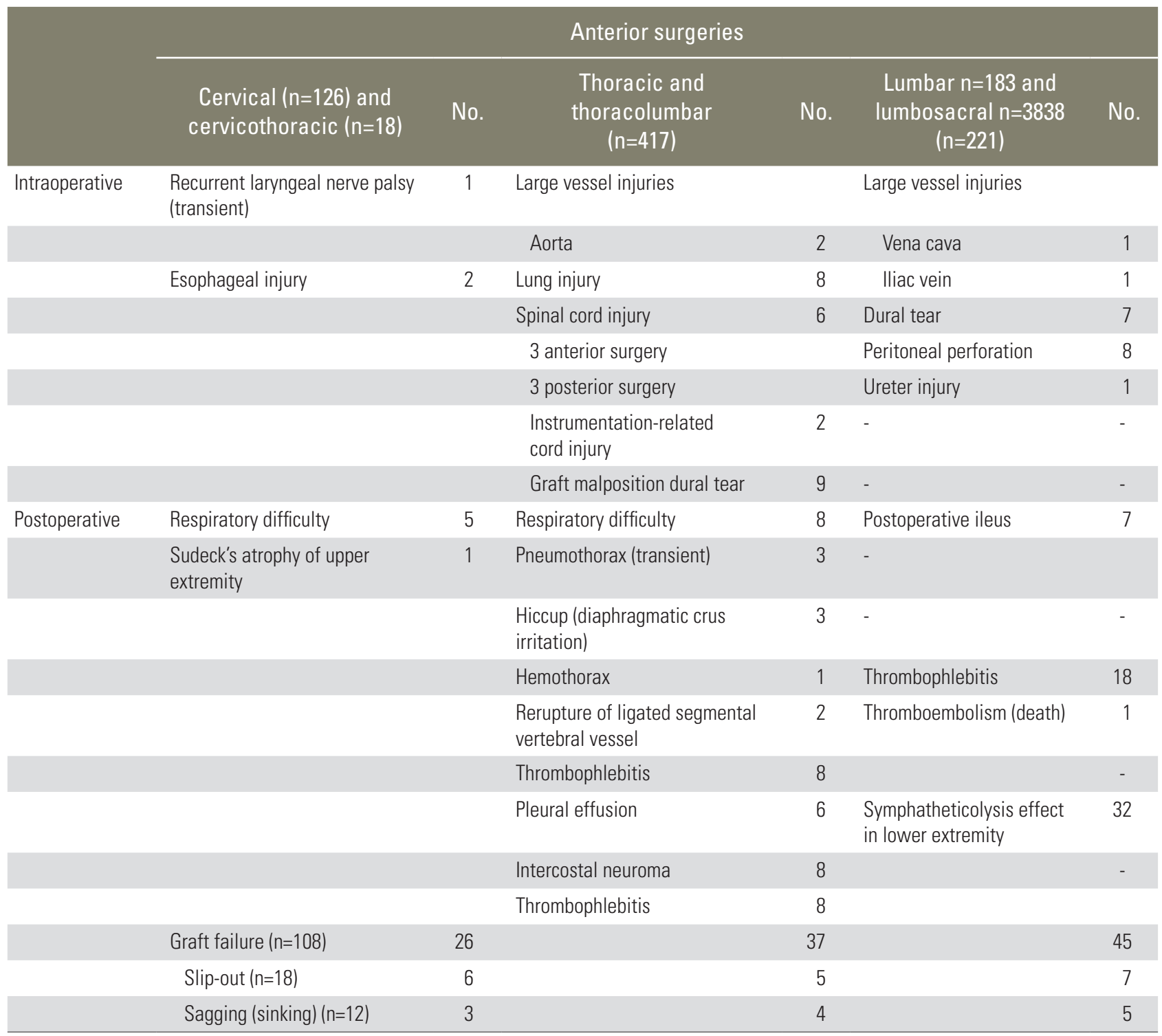


compression was suspected in eight late onset progressive paraparetics, and five did not recover. One dural tear formed a fistula for an extended period. There were no complications directly associated with posterior instrumentation, but one rod loosening developed in a child (Fig. 2).

\section{Anterior surgery-related complications}

1) Anterior cervical procedure-related complications (126 surgeries)

There were five different types of complications: one transient recurrent laryngeal nerve palsy; two esophagus perforations; five acute respiratory distress; and one Sudek's atrophy of the left arm (Tables 2, 3). Graft slipped out from the graft-bed in one case (Fig. 3).

2) Thoracic and thoracolumbar approach-related complications

There were complications in 417 left anterolateral thoracotomy procedures (125 dorsal and 292 dorsolumbar) (Tables 2, 3). Major complications were the traumatic aorta ruptures in two and direct cord injuries in three (one by decompression procedure; one by chisel tip; and one by malpositioned graft bone) (Fig. 1). There were nine accidental dural tears, but cord was not directly bruised. Postoperatively there were 38 thoracic cavity complications (Table 3). Thrombophlebitis developed in the lower extremities of eight patients. One female patient with spastic paraparesis died of sudden thromboembolism, at 12 days after anterior decompression.

3) Lumbar and lumbosacral approach-related complications There were accidental dural tears in seven patients. There were sympatheticolysis symptoms and signs (70\%) in the lower extremities in 32 cases and thrombophlebitis (40\%) in 18 cases. Accidental ureteral ligation in a young woman was confirmed very late and resulted in hydronephrosis (Tables 2, 3).

4) Complications related with instrumentation surgery Cords were injured during the instrument-aided deformity correction in three cases, and there was a fixation failure in one child (Rush nail migration) (Fig. 4).
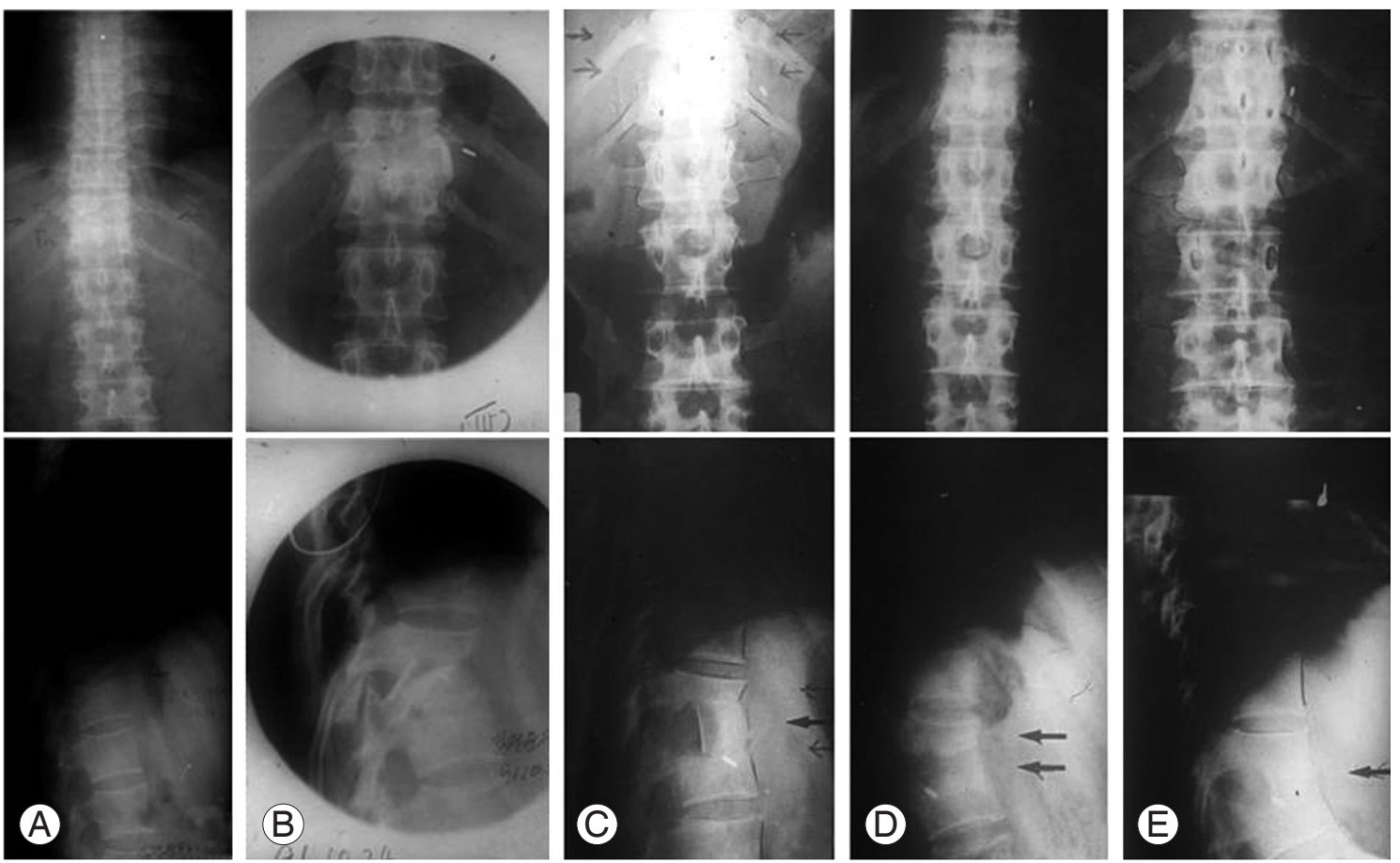

Second operation (AIF)

Fig. 1. (A) A malpositioned obliquely tilted strut graft in the neural canal at the time of anterior radical surgery for the tuberculosis of $T_{11-12}$. (B) The malpositioned graft was repositioned between $T_{11-12}$ more anteriorly (C), which was well incorporated with the graft beds (D, E). Arrow indicates the grafted site. AlF, anterior interbody fusion. 

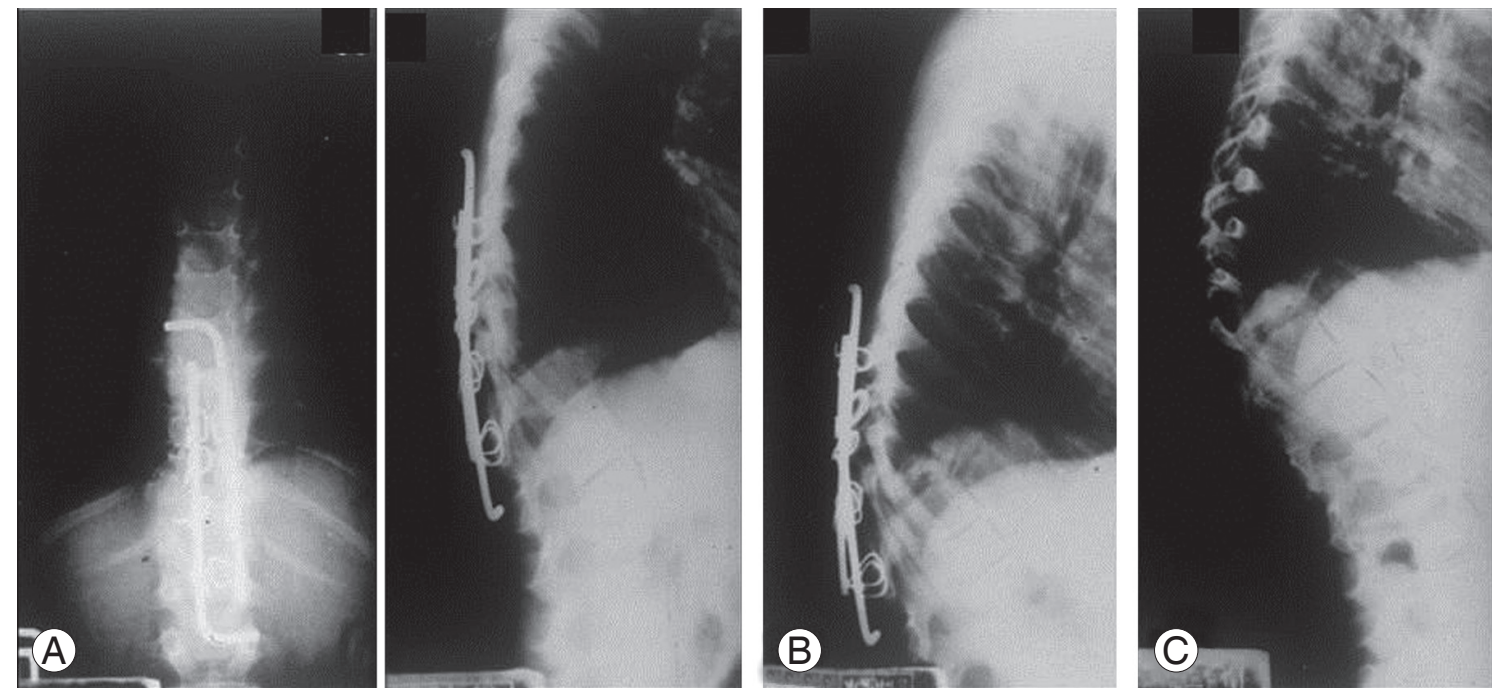

Fig. 2. (A) Tuberculous kyphosis at $T_{11-12}$ in a 6-year-old boy was posteriorly stabilized with two Rush nails and segmental wiring between $T_{9}-L_{1}$, under the cover of the triple chemotherapy (INH, rifampin, ethambutol). (B) Tuberculosis was well-cured, but the tip of the inferiorly migrated Rush nail caused pain in the back with a slight progress of kyphosis. (C) The fixation devices were removed, as it did not perform. After removal of the instrument, kyphosis progressed further because of the residual wedging of the diseased vertebra.
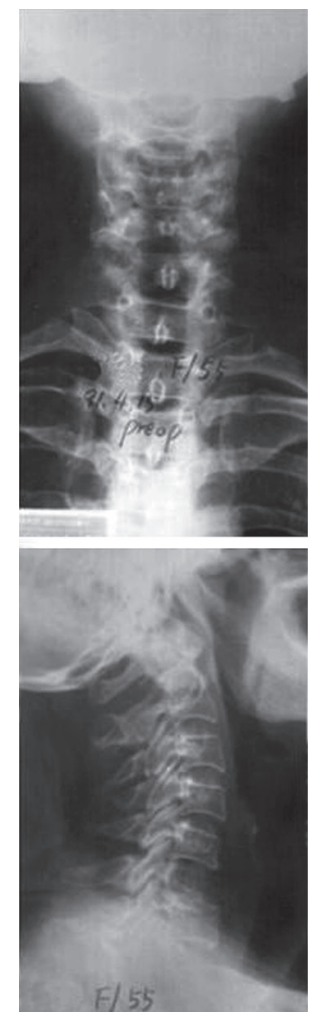

(A)
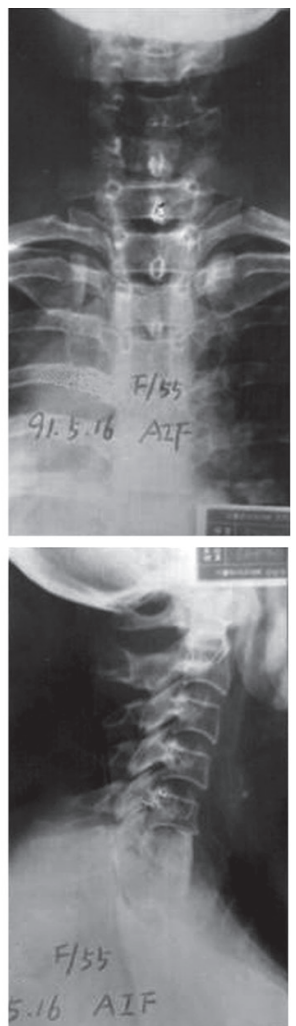

B
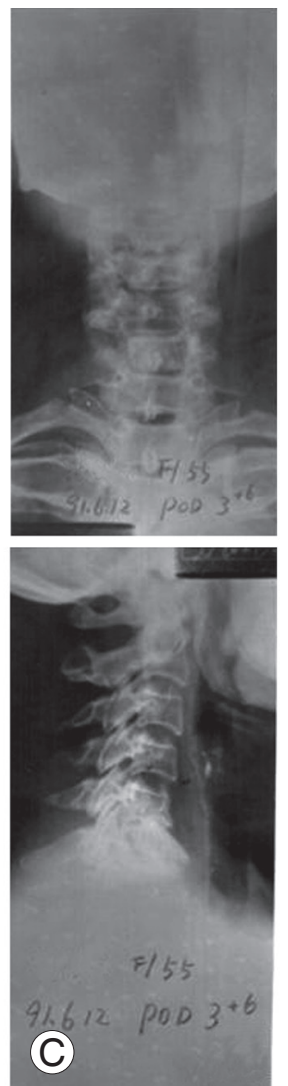
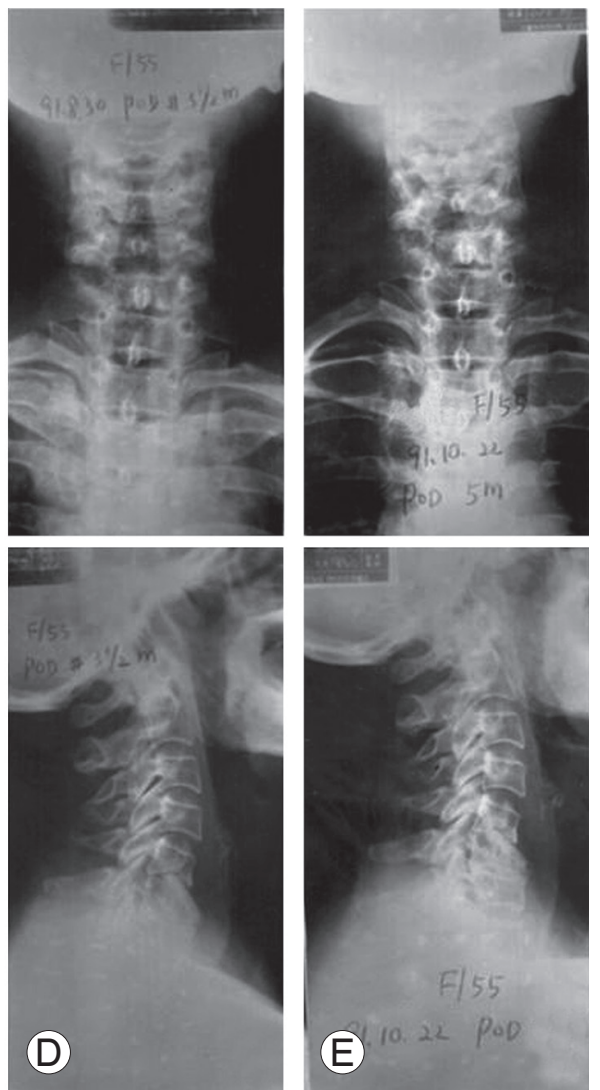

Fig. 3. A 55-year-old lady with tuberculosis of $C_{5-7}$ (A) for which anterior radical debridement and fusion with an iliac strut graft (B) were performed, under the cover of triple antituberculous medication. The lower end of the iliac strut graft slipped out from the graft bed of $\mathrm{C}_{7}(\mathrm{C})$. It healed with solid consolidation without causing respiratory difficulty and dysphagia $(\mathrm{D}, \mathrm{E})$. 
5) Failure in achieving surgical goal

Various types of surgical failures are listed in Tables 2, 3. The major failures were non-neurological recovery after decompression and/or aesthetically unacceptable postsurgical residual deformity. Seven (10.7\%) out of 65 adult Pott's paraplegics did not recover neurologically; and two $(7.4 \%)$ out of 27 paraplegic children did not recover.
Non-instrumented posterior fusion in seven patients for the dorsal and dorsolumbar kyphosis could not maintain the pre-existed kyphosis and/or prevent the progress of kyphosis, particularly during growth.

The main sequelae of the bony spinal column in children were the aesthetically unacceptable residual deformity and its progress after surgical debridement alone
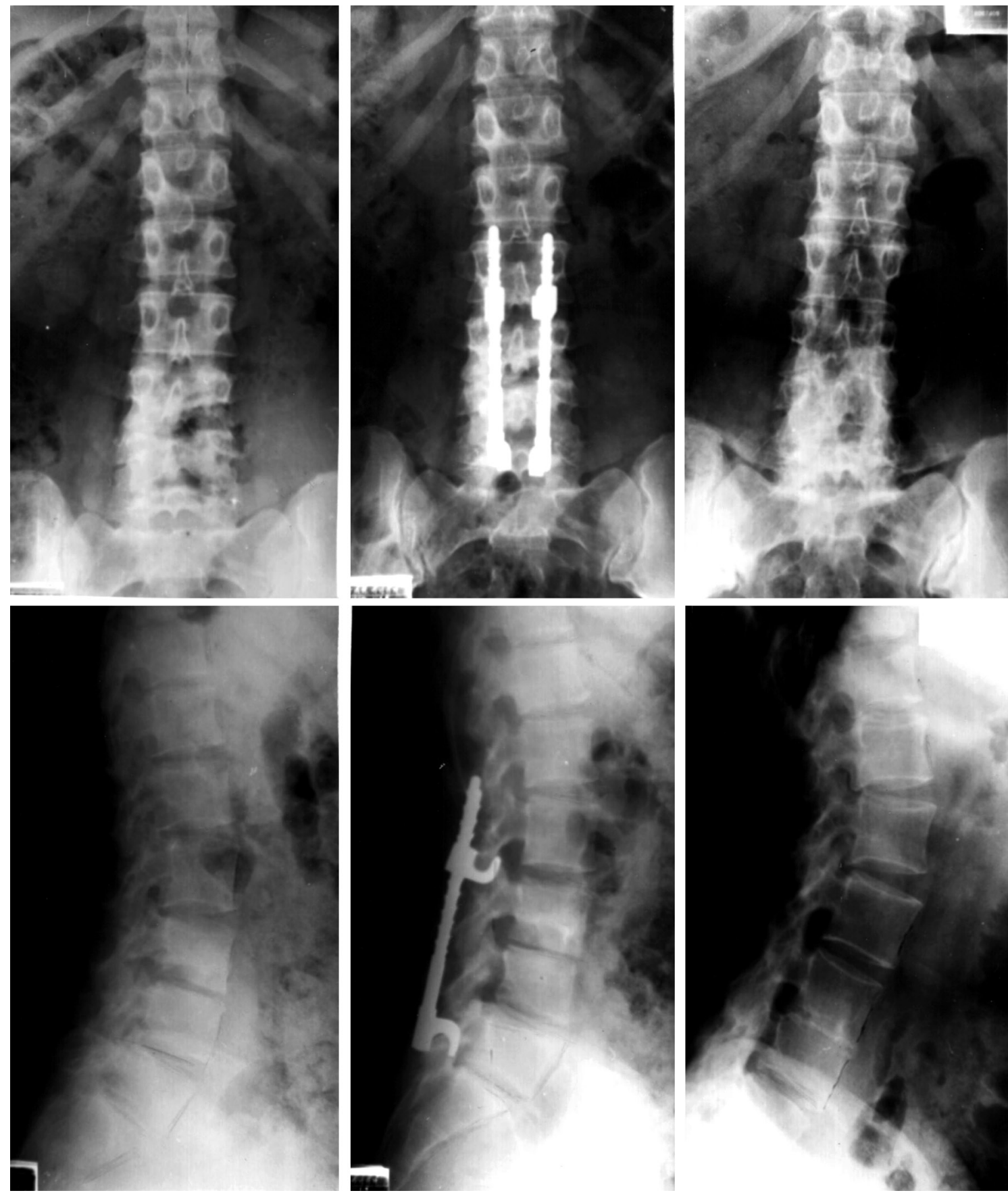

Fig. 4. Adjacent joint disease after Harrington's distraction instrumentation. Posteriorly fused $L_{2}-S_{1}$ with flat back deformity and anteriorly fused $L_{3-4}$ and hyperextended $T_{12}-L_{1}$ and $L_{1}-L_{2}$ are shown. Positive sagittal balance is shown. 
and noninstrumented posterior or anterior fusion during and after healing. Gradual increase of kyphosis due to anterior growth arrest occurred in 97 children (43\%), in spite of the restored stability of the diseased segments.

There were overall anterior strut graft collapse in 108 cases (14.3\%): 26 in cervical, 37 in thoracic, and 45 in lumbar spines. The grafts slipped out from graft beds in eighteen (2.3\%): 6 in cervical, 5 thoracic, and 7 in lumbar spines. The graft sagging into graft beds were found in the following: 3 cervical AIF; 4 thoracic AIF; and 5 lumbar AIF.

Anterior fusion failure occurred in one adult with a mixed infection of E. coli among the 764 anterior surgery patients.

\section{Discussion}

There is a large body of literature on the tuberculosis of spine [1,3-24]. Most of the studies report on the methods and results of management. However, none have dealt solely with the management-related complications and sequelae, particularly the surgery-related ones. Therefore, it is thought that the current retrospective study on the intra- and postoperative complications and sequelae is timely, providing the basic data for the future comprehensive comparative studies [9-13].

Surgical procedures play an important role in spite of the accompanying risks in the management of the complicated spinal tuberculosis [18-24]. When the primary surgical goals aiming at the deformity prevention and/ or correction and neural recovery were not achieved, the results were judged as a failure in spite of the healed disease. There are a number of potential and formidable intraoperative and postoperative complications associated with any surgical procedure. It was once thought that if the surgery was confined to the treatment of tuberculosis itself, surgery-related complications and residuals could be prevented and/or minimized $[11,13,14]$. Generally it was known that the surgical complication rates were higher in the deformity correction surgery [14,23], and that the surgical intervention for the advanced tuberculosis was fraught with complications and poor results, especially when the surgery was carried out without solid judgment.

The current authors found that the development of surgical complications was greatly influenced by the patient and surgeon factors, with the following six factors especially to be considered: patient's age and general con- dition, cord condition, severity of deformity, emergency surgery, unjustified surgical indication, and surgeon's skills.

The reported complications were vascular and neurological injuries, thoracic cavity problems, thrombophlebitis, infection, pseudarthrosis, bed sores, superior mesenteric artery syndrome, ileus, wound dehiscence, subcutaneous metal prominence and painful adventitious bursitis over the metal and hardware and/or fixation failure [14].

Some of the most serious complications in the current series were the injuries of the large vessels, cord and nerves, lung, esophagus and ureter. In Rajasekaran et al.s [17] series of 17 patients with severe kyphosis, the complication rates were 5 patients $(29.4 \%)$ temporary neurological deterioration in 1 (5.9\%); superficial wound infection in $2(11.7 \%)$; and jaundice in 1 (5.9\%). In Lee et al.s [10] series of 16 patients who underwent posteriorly instrumented lumbar interbody fusion, complications occurred in 4 patients (25\%): wound infection and transient nerve root injury in 2 (12.5\%), respectively. This fact indirectly suggests that the posterior interbody fusion is not a safe procedure.

In the postoperative complications, $10 \%-30 \%$ incidence of the cardiac, vascular, gastrointestinal and technical complications were reported by Cheung and Al Ghazi [2]. However, we did not encounter cardiac complications.

Recurrent laryngeal nerve and esophagus injuries and prevertebral hematoma associated with anterior cervical surgery can be listed as serious complications. Sudeck's atrophy of the upper extremity may be listed as one of the late complications of anterior cervical surgery.

In the current series, respiratory distress developed in five patients after anterior cervical surgery and thirtyeight after thoracotomy procedures (Table 2). Acute respiratory difficulty due to cervical hematoma compressing the trachea and/or cervical cord above $\mathrm{C}_{4}$ and due to the slipped graft bone should be managed urgently $[2,4,5]$.

Among the early postoperative complications, thromboembolism associated with thrombophlebitis was the most grave $[11,12]$. Among the complications related with the anterior thoracic procedures, there were injuries of large vessels and lung [3]. Two patients with aorta rupture did not recover.

Possible cord ischemia by segmental artery ligation at level of $\mathrm{T}_{4}-\mathrm{T}_{9}$ has been listed as one of the most important anterior thoracic surgery-related complications. Cheung and Al Ghazi [2] strongly advised that when the 
$\mathrm{T}_{4}-\mathrm{T}_{9}$ bodies are approached, segmental arteries should be divided close to their origins to enable collateral circulation through the internal mammary and intercostal arteries to minimize the cord infarction. However, unilateral division of segmental arteries at their origin rarely resulted in cord ischemia [2]. The more the levels of ligation, higher were the risk of spinal cord ischemic damage; and bilateral ligation in case of the total spondylectomy was at a higher risk than the unilateral ligation. In the current series, cord ischemia did not complicate.

Also paralysis secondary to cord stretch ischemia could occur during instrument-aided distractive correction of severe thoracic spinal deformities, though the incidence was reported to be less than $1 \%$ [2]. We did not encounter paralysis by cord stretch ischemia by adjusting the cord and canal length equal during correction, though the cord was directly injured during corrective osteotomy in two [13]. Eight thoracic spinal roots injuries were complicated, which did not affect the patient's activity.

Cheung and Al Ghazi [2] reported that atelectasis, pneumothorax, pneumonia and even death were complicated in up to $50 \%$ of both adult and pediatric patients. Chylothorax did not complicate in the current series; and none of the 24 surgery-related dural tears required dural closure and reoperation.

Among the anterior lumbar and lumbosacral surgeryrelated complications, the most serious was the injury of the vena cava and iliac vein, which could secondarily precipitate the thrombophlebitis. Also despite the advantages of the anterior surgery, troubling complications such as ileus, incisional hernia, urinary retention, retrograde ejaculation were reported [10].

The thrombophlebitis and sympatheticolysis symptoms and signs in the lower extremities were more frequently complicated in the anterior surgery. A Pott's paraparetic woman who had anterior thoracic decompression died suddenly of thromboembolism. The sympatheticolysis symptoms were bothersome, though they could be overcome.

There were graft collapse and sagging after uninstrumented AIF. Thus, instrumentation was found to be helpful to prevent the graft collapse and slip-out, to maintain the corrected alignment and to hasten the intercorporal fusion. Also combined AIF and short segment instrumentation was the most recommendable procedure, which could provide the secure fixation until healing of the disease and established fusion. However, it is re- minded that instrumentation can increase the rate of complication. Some authors doubted the unsubstantiated concept and/or rationale that complete deformity correction is essential [14].

Careful preoperative surgical planning and patientcare, improved surgical technique and postoperative patient management are thought to be the most important factors to minimize the complications and residuals. Any decision to operate should be based on the goal of treatment for each individual, and must weigh the high complication and reoperation rates against the anticipated improvement. Surgical risks and complications must be fully understood, and the patients must ultimately choose between the risks and his/her quality of life.

This study has limitations: non-homogenous material subjects of different ages; differences in surgical management and surgeon's skill; and different observation time for each individual. All the cases were operated under the senior author's surgical guidelines, in spite of the evolutionary changes of the management in the last 41 years.

Lastly it is reminded that surgical management is not 'salvage' oriented, and that the patients and surgeons must have realistic expectations about the anticipated results. Surgical risks and complications must be fully understood to the patient and his or her support group through informed consent discussions. Some of the complications were not caused by the surgeons' faults; however, the treating surgeons were faced with demanding difficulties over the results.

\section{Conclusions}

If the suggested treatment guidelines were kept and the unnecessary extra-surgery were not combined, the surgical complications and residuals could be prevented or minimized (Tables 2, 3) in the spinal tuberculosis surgery. Surgery should be reserved only for the complicated cases of spinal tuberculosis in patients for whom surgery is definitely indicated. Highly evolved surgical technique, improved surgical tools and newly developed anti-tubercular drugs are contributing greatly in reducing the surgical complications.

\section{Conflict of Interest}

No potential conflict of interest relevant to this article was reported. 


\section{References}

1. Chen WJ, Chen CH, Shih CH. Surgical treatment of tuberculous spondylitis: 50 patients followed for 2-8 years. Acta Orthop Scand 1995;66:137-42.

2. Cheung KM, Al Ghazi S. Approach-related complications of open versus thoracoscopic anterior exposures of the thoracic spine. J Orthop Surg (Hong Kong) 2008;16:343-7.

3. Fountain SS, Hsu LC, Yau AC, Hodgson AR. Progressive kyphosis following solid anterior spine fusion in children with tuberculosis of the spine. A long-term study. J Bone Joint Surg Am 1975;57:1104-7.

4. Faciszewski T, Winter RB, Lonstein JE, Denis F, Johnson L. The surgical and medical perioperative complications of anterior spinal fusion surgery in the thoracic and lumbar spine in adults. A review of 1223 procedures. Spine (Phila Pa 1976) 1995;20:1592-9.

5. Grossfeld S, Winter RB, Lonstein JE, Denis F, Leonard A, Johnson L. Complications of anterior spinal surgery in children. J Pediatr Orthop 1997;17:89-95.

6. Hassan MG. Anterior plating for lower cervical spine tuberculosis. Int Orthop 2003;27:73-7.

7. Hodgson AR, Stock FE. Anterior spine fusion for the treatment of tuberculosis of the spine: the operative findings and results of treatment in the first one hundred cases. J Bone Joint Surg Am 1960;42:295-310.

8. Jain AK, Aggarwal PK, Arora A, Singh S. Behaviour of the kyphotic angle in spinal tuberculosis. Int Orthop 2004;28:110-4.

9. Kalra KP, Dhar SB, Shetty G, Dhariwal Q. Pedicle subtraction osteotomy for rigid post-tuberculous kyphosis. J Bone Joint Surg Br 2006;88:925-7.

10. Lee JS, Moon KP, Kim SJ, Suh KT. Posterior lumbar interbody fusion and posterior instrumentation in the surgical management of lumbar tuberculous spondylitis. J Bone Joint Surg Br 2007;89:210-4.

11. Moon MS, Woo YK, Lee KS, Ha KY, Kim SS, Sun DH. Posterior instrumentation and anterior interbody fusion for tuberculous kyphosis of dorsal and lumbar spines. Spine (Phila Pa 1976) 1995;20:1910-6.

12. Moon MS, Ha KY, Sun DH, Moon JL, Moon YW, Chung JH. Pott's Paraplegia: 67 cases. Clin Orthop Relat Res 1996;(323):122-8.

13. Moon MS. Tuberculosis of the spine. Controversies and a new challenge. Spine (Phila Pa 1976) 1997;22:
1791-7.

14. Moon MS, Kim SS, Lee BJ, Moon JL, Moon YW. Surgical management of severe rigid tuberculous kyphosis of dorsolumbar spine. Int Orthop 2011;35:75-81.

15. Nagariya S, Patgaonkar P, Chhabra S, Agrawal V, Franke J. Single stage anterior decompression and instrumentation for spinal tuberculosis. J Spinal Surg 2010;2:373-82.

16. Pun WK, Chow SP, Luk KD, Cheng CL, Hsu LC, Leong JC. Tuberculosis of the lumbosacral junction: long-term follow-up of 26 cases. J Bone Joint Surg Br 1990;72:675-8.

17. Rajasekaran S, Vijay K, Shetty AP. Single-stage closing-opening wedge osteotomy of spine to correct severe post-tubercular kyphotic deformities of the spine: a 3-year follow-up of 17 patients. Eur Spine J 2010;19:583-92.

18. Sengupta DK, Grevitt MP, Mehdian SM. Hypoglossal nerve injury as a complication of anterior surgery to the upper cervical spine. Eur Spine J 1999;8:78-80.

19. Sundararaj GD, Behera S, Ravi V, Venkatesh K, Cherian VM, Lee V. Role of posterior stabilisation in the management of tuberculosis of the dorsal and lumbar spine. J Bone Joint Surg Br 2003;85:100-6.

20. Upadhyay SS, Sell P, Saji MJ, Sell B, Yau AC, Leong JC. 17-year prospective study of surgical management of spinal tuberculosis in children. Hong Kong operation compared with debridement surgery for short- and long-term outcome of deformity. Spine (Phila Pa 1976) 1993;18:1704-11.

21. Upadhyay SS, Saji MJ, Sell P, Yau AC. The effect of age on the change in deformity after radical resection and anterior arthrodesis for tuberculosis of the spine. J Bone Joint Surg Am 1994;76:701-8.

22. Upadhyay SS, Saji MJ, Yau AC. Duration of antituberculosis chemotherapy in conjunction with radical surgery in the management of spinal tuberculosis. Spine (Phila Pa 1976) 1996;21:1898-903.

23. Yau AC, Hsu LC, O’Brien JP, Hodgson AR. Tuberculous kyphosis: correction with spinal osteotomy, halo-pelvic distraction, and anterior and posterior fusion. J Bone Joint Surg Am 1974;56:1419-34.

24. Yilmaz C, Selek HY, Gurkan I, Erdemli B, Korkusuz Z. Anterior instrumentation for the treatment of spinal tuberculosis. J Bone Joint Surg Am 1999;81:1261-7. 